\title{
Discrete pleural masses without effusion in a young man: an unusual presentation of tuberculosis
}

\author{
S B BLUNT, M G HARRIES \\ From the Department of Respiratory Medicine, Northwick Park Hospital, Harrow, Middlesex
}

\begin{abstract}
Extensive tuberculous infection of the pleura presented radiographically as multiple discrete nodules, without associated effusion or lesions of lung parenchyma.
\end{abstract}

Pleural effusion is a recognised complication of primary and postprimary tuberculosis. In about two thirds of cases there is no associated parenchymal lesion on the chest radiograph; ${ }^{23}$ tubercle bacilli are frequently found in biopsy specimens of pleural tissue.

We report widespread tuberculous infection of the pleura presenting as multiple discrete nodules without effusion

\section{Case report}

A 29 year old male Ugandan Asian, resident in Britain for nine years, presented with reduced appetite and weight loss of about a year's duration. He complained of pleuritic pain in the left axilla, exertional dyspnoea, and a dry cough. One month before presentation he developed night sweats. His wife had received treatment for pulmonary tuberculosis five years before, and he had been followed up as a contact of his wife for 18 months after her diagnosis. A chest radiograph in 1984, at the end of this follow up period, was normal. He had never been exposed to asbestos.

On examination he was thin but looked well. Breath sounds were reduced at the left posteriorly, but the percussion note was normal. There was scoliosis to the right. The remaining clinical examination showed nothing abnormal. Electrolyte concentrations and results of liver function tests were normal, but a full blood count indicated hypochromic microcytic anaemia $(12.4 \mathrm{~g} / \mathrm{l})$. The erythrocyte sedimentation rate was $65 \mathrm{~mm}$ in the first hour. The Mantoux test produced a $3 \mathrm{~cm}$ induration with one tuberculin unit $(0.1 \mathrm{ml}$ of 1:10 000). A chest radiograph showed multiple discrete, noncalcified opacities throughout the pleura of the left hemithorax without associated effusion or parenchymal lung disease (fig 1). A computed tomography scan of the thorax confirmed multiple pleural masses in the left hemithorax with more generalised thickening at the apex and base, but there was no evidence of fluid. The right hemithorax appeared normal (fig 2). Needle biopsy of a pleural mass revealed a granuloma with central caseation containing many acid fast bacilli. Cultures of sputum, urine, and gastric washings were

Address for reprint requests: Dr S B Blunt, Department of Neurology, Institute of Psychiatry, London SE5 8AF.

Accepted 8 February 1989

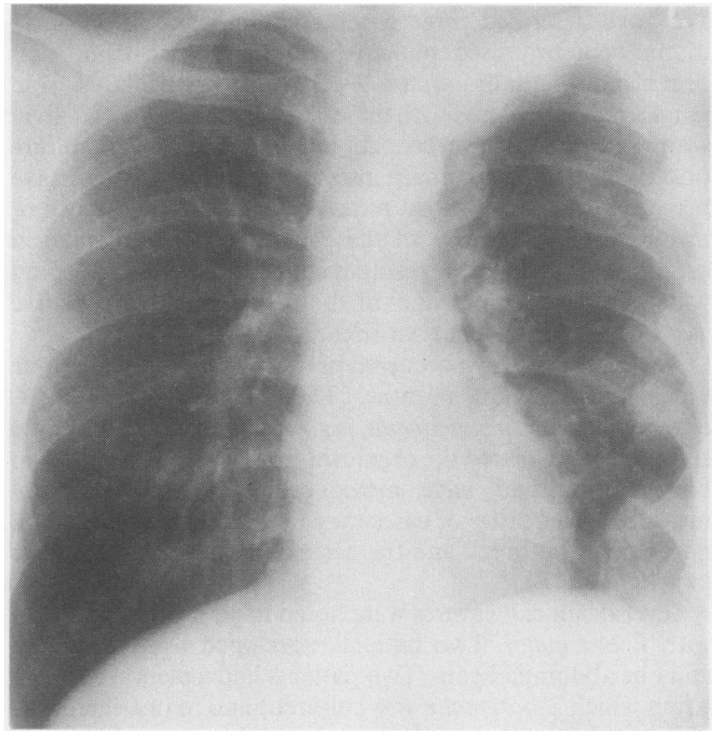

Fig 1 Chest radiograph showing multiple peripheral masses in the left hemithorax, without evidence of associated pleural effusion.

all negative. At no stage during the illness did a pleural effusion develop. The patient started antituberculous treatment, with resolution of his symptoms within one month. The erythrocyte sedimentation rate returned to normal, and a repeat chest radiograph two months after the start of treatment showed that the opacities were decreasing in size.

\section{Discussion}

Discrete pleural masses may occur in mesothelioma, certain pneumoconioses (mica, talc), myeloma, lymphoma, ${ }^{4}$ and metastases. Pleural thickening may also result from any longstanding inflammatory condition-for example, haemothorax, empyema, tuberculous effusion, or recurrent pneumothorax, often with calcification. Pulmonary tuberculosis produces a broad range of radiographic appearances, ${ }^{5}$ but tuberculous infection causing pleural disease as extensive as this and without effusion is unusual. Pleural infection in tuberculosis is usually characterised by an effusion in the acute stage, or by diffuse thickening of the pleura - often with calcification - in longstanding cases. ${ }^{6}$ So far as we are aware, 


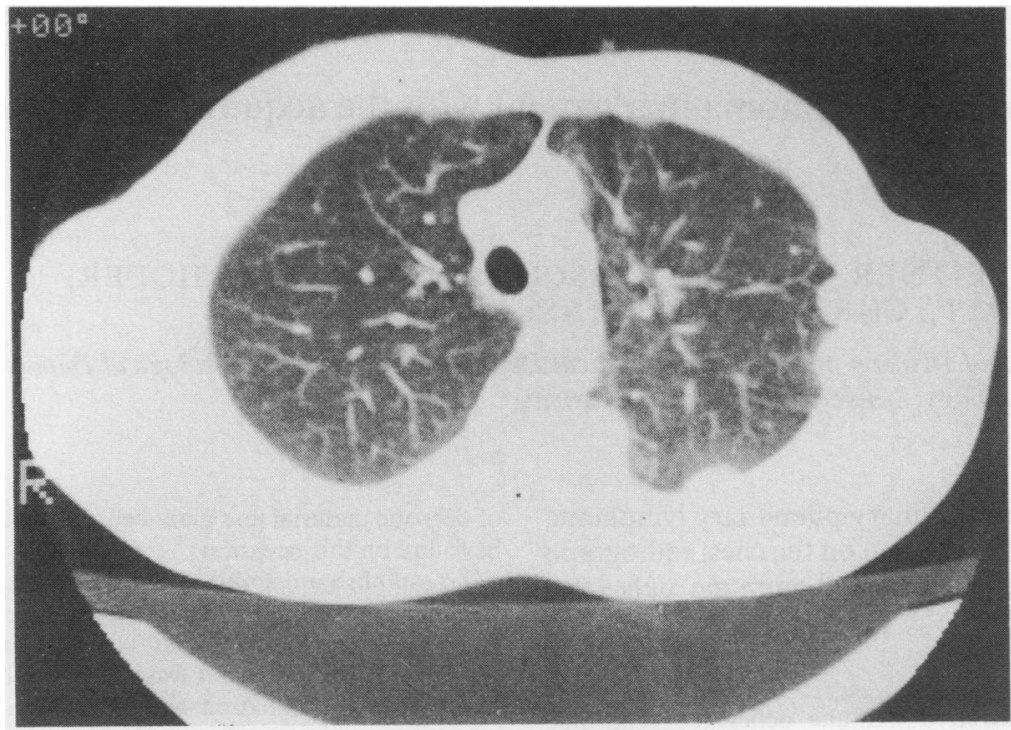

Fig 2 Computed tomogram of the thorax showing multiple pleural masses in the left hemithorax with a normal mediastinum and lung parenchyma.

pleural tuberculosis presenting as discrete pleural masses as its sole radiographic manifestation has not been reported before. We suggest that tuberculosis should be considered in the differential diagnosis of pleural masses even when there is no associated effusion or radiographically visible parenchymal lung disease.

\section{References}

1 Herbert A. Pathogenesis of pleurisy, pleural fibrosis, and meso- thelial proliferation. Thorax 1986;41:176-89.

2 Light RW. Pleural diseases. Philadelphia: Lea and Febiger, 1983:119-25.

3 Berger HW, Mejia E. Tuberculous pleurisy. Chest 1973;63:88-92.

4 Sargent EN, Jacobson G, Gordonson JS. Pleural plaques: a signpost of asbestos inhalation. Semin Roentgenol 1977;12:287-97.

5 Woodgring JH, Mac Vandiviere H, Fried AM, Dillon ML, Williams TD, Melvin IG. Update: The radiographic features of pulmonary tuberculosis. AJR 1986;146:497-506.

6 Palmer PE. Pulmonary tuberculosis-usual and unusual radiographic presentation. Semin Roentgenol 1979;14:204-43. 